\title{
JOGANDO COM AS FEMINILIDADES: UM ESTUDO ETNOGRÁFICO EM UM TIME DE FUTSAL FEMININO DE PORTO ALEGRE**
}

\author{
Ms. RAQUEL DA SILVEIRA \\ Mestre em Ciências do Movimento Humano da Universidade Federal do Rio Grande do Sul \\ (UFRGS), Professora do curso de Educação Física da Universidade Federal do Rio Grande (FURG) \\ (Rio Grande - Rio Grande do Sul - Brasil) \\ E-mail: raqkarate@hotmail.com

\section{DR. MARCO PAULO STIGGER} \\ Doutor em Ciências do Desporto e Educação Física da Universidade do Porto (UP - Portugal), \\ Professor adjunto na Escola de Educação Física da Universidade Federal do Rio Grande do Sul \\ (UFRGS) (Porto Alegre, Rio Grande do Sul, Brasil) \\ E-mail: stigger@adufrgs.ufrgs.br
}

\begin{abstract}
RESUMO
Esse estudo aborda o associativismo esportivo de mulheres. Trata-se de uma investigação etnográfica desenvolvida no contexto de um time de futsal feminino, onde procuramos saber como e porque mulheres se associam para praticar um esporte socialmente considerado masculino, e como essa prática se insere nas suas vidas. Após um ano de observação participante (diários de campo) e realização de entrevistas ( I 7), identificamos que a prática do futsal extrapola o jogo propriamente dito, sendo fortemente vinculada a questões de gênero e sexualidade presentes dentro e fora da quadra. Na relação com o esporte que elas escolheram praticar, esses temas se entrelaçavam no cotidiano das jogadoras, de forma heterogênea: se, por um lado, identificamos uma transgressão em relação aos padrões dominantes, por outro, também visualizamos a reprodução desses mesmos valores.
\end{abstract}

PALAVRAS-CHAVES: Gênero; sexualidade; futsal; mulheres.

1. A pesquisa foi financiada pela CAPES através de uma bolsa de mestrado. 
É difícil discordar de Dunning quando, ao dizer que o esporte é "tradicionalmente uma das mais importantes áreas reservadas masculinas" (DUNNING, 1992, p. 390), chama atenção para a generificação dos esportes. E, se a afirmativa é verdadeira no contexto geral dos esportes, bem mais flagrante isto se mostrará se o foco forem os esportes considerados socialmente como masculinos, o que é o caso do futebol, no Brasil. Talvez seja possível afirmar que, ao contrário da importância que as práticas esportivas tiveram para com a constituição das masculinidades, a participação das mulheres nos esportes não se constituiu em elemento importante para a construção de uma feminilidade hegemônica. Historicamente falando, mesmo no contexto dos esportes onde a participação das mulheres era aceita, não havia o reconhecimento destes como práticas que destacassem a feminilidade hegemônica. ${ }^{2}$ Ao contrário disso, certos esportes eram proibidos para elas, o que se sustentava de várias formas, entre as quais a partir da alegação acerca dos problemas que Ihes poderiam causar, principalmente os relacionados à maternidade. Conforme Goellner (2005a, p. 92),

o suor excessivo, o esforço físico, as emoções fortes, as competições, a rivalidade consentida, os músculos delineados, os gestos espetacularizados do corpo, a liberdade de movimentos, a leveza das roupas e a seminudez, práticas comuns ao universo da cultura física, quando relacionadas à mulher despertavam suspeitas porque pareciam abrandar certos limites que contornavam uma imagem ideal de ser feminina. Pareciam, ainda, desestabilizar o terreno criado e mantido sob o domínio masculino cuja justificativa, assentada na biologia do corpo e do sexo, deveria atestar a superioridade deles em relação a elas.

Mesmo assim, Guttman (1978), Rubio e Simões (1999) e Goellner (2005a) constataram a presença de mulheres na história do esporte. Em I 832, por exemplo, foram fundadas as primeiras instalações de ginástica para as mulheres alemãs, embora a primeira competição importante ocorresse apenas em I 9 I3 (GUTTMAN, 1978). Em 1900, na segunda edição dos Jogos Olímpicos Modernos, realizada em Paris, as mulheres participaram da modalidade de golfe e de tênis (RUBIO; SIMÕES, 1999). Em 1932, na Olimpíada sediada em Los Angeles, "o Brasil registraria a participação de sua primeira atleta: a nadadora paulista Maria Lenk” (GOELLNER, 2005a, p. 88). Esses fatos permitem dizer que, apesar do predomínio dos homens na história do esporte, as mulheres se fizeram presentes mesmo que timidamente.

2. Conforme Louro (200 I) a feminilidade e masculinidade hegemônica são construídas a partir de investimentos e pedagogias de inúmeras instâncias da nossa sociedade. Os exemplos de vida trazidos pela autora reforçam a associação do esporte enquanto um meio de produzir "uma determinada forma de masculinidade" (LOURO, 2001 , p. 17) considerada quase que como uma norma. 
Nos dias de hoje é evidente que elas estão presentes no mundo esportivo, o que se percebe, também, pelo interesse dos intelectuais sobre o tema. Numa revisão bibliográfica sobre o que foi produzido a respeito da temática mulheres e esportes, constatamos diversas abordagens sobre o assunto. Porém, a partir da análise dessa bibliografia, dois aspectos nos chamaram atenção: I) existem vários estudos sobre a participação das mulheres nos esportes socialmente considerados masculinos, quando os protagonistas são os homens; 2) no entanto, é menor o número de trabalhos que tratam da participação das mulheres nesse mesmo tipo de esporte, mas na condição de praticantes.

No primeiro caso, constatamos que as mulheres ocupam espaço secundário na prática esportiva: são torcedoras, mães, irmãs, articulistas, e até mesmo prostitutas (SAOUTER, 2003) no contexto das práticas esportivas realizadas pelos homens. Alguns exemplos desses estudos são: "A mamãe e a prostituta: os homens, as mulheres e o rugby" (SAOUTER, 2003); "Futebol é 'coisa para macho'? Pequeno esboço para uma história das mulheres no país do futebol" (FRANZINI, 2005); "O que é uma torcedora? Notas sobre a representação e auto-representação do público feminino de futebol" (COSTA, 2006/2007); "Copa do Mundo de 2006: o que elas escreveram na Folha de São Paulo" (SILVEIRA, 2007).

No segundo item de nossa análise, percebemos que a atenção se direciona às mulheres quando elas são as protagonistas dos esportes. Aqui, o campo empírico relaciona-se aos esportes socialmente considerados masculinos praticados por muIheres: "Mulheres e futebol no Brasil: entre sombras e visibilidades" (GOELLNER, 2005b); "Ser mulher no mundo dos homens: socialização esportiva e a construção do gênero" (MENNESSON, 2005); "As narrativas sobre o futebol feminino: o discurso da mídia impressa em campo" (MOURÃO; MOREL, 2005); "Os processos de construção e de modificação das disposições sexuais das mulheres que investem em esportes ditos 'masculinos'” (MENNESSON, 2004); "O futebol feminino de várzea: uma análise cultural" (DORNELLES, 2004); "Homossociabilidade e homossexualidade: o caso de mulheres jogadoras de futebol" (MENNESSON, CLÉMENT, 2003).

Existem, portanto, diversos estudos sobre essa temática, mas a forma como acontecem esses esportes, a compreensão do associativismo dessas praticantes e os significados atribuídos por elas à prática são pouco explorados. E é devido à pouca quantidade de estudos sobre esse recorte da temática que desenvolvemos esta pesquisa, a fim de compreender aspectos do associativismo feminino em esportes socialmente considerados masculinos. Para localizar este estudo, construímos a Figura 1 . 


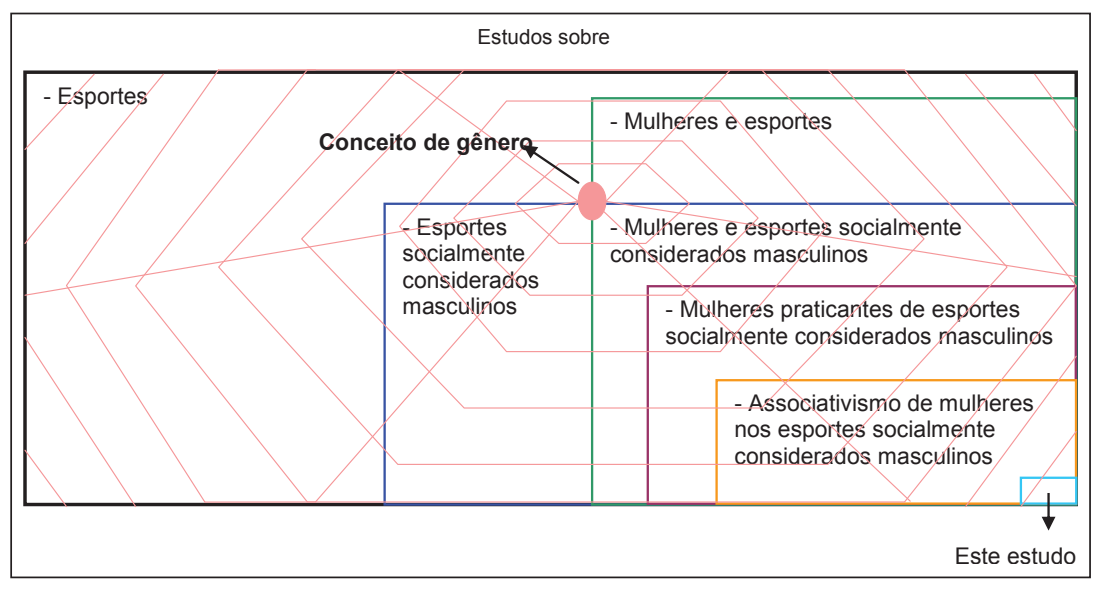

Figura I. Localização deste estudo no campo dos esportes e suas relações com o conceito de gênero Fonte: elaboração própria

A partir da Figura I, procuramos mostrar que este estudo se insere na intersecção de dois grandes temas: "mulheres e esportes" e "esportes socialmente considerados masculinos". Nesse contexto, a investigação apresenta uma análise específica da temática e chega aos estudos sobre o associativismo entre mulheres nos esportes socialmente considerados masculinos. Tendo em vista que tanto "esportes e mulheres" quanto "esportes socialmente considerados masculinos" são atravessados por relações de gênero, entendemos que, na intersecção desses temas, este conceito inicia o centro de uma teia que atravessa todo o trabalho e apresenta-se como pressuposto das análises que realizamos.

A partir dessa breve explanação, desenvolvemos uma pesquisa com o objetivo de compreender aspectos do associativismo feminino num esporte socialmente visto como masculino, tendo como universo empírico um grupo de mulheres praticantes de futsal, ${ }^{3}$ na cidade de Porto Alegre. Naquele contexto, perguntamos: como e porque mulheres se associam para praticar um esporte socialmente considerado masculino? Quais as estratégias e formas de funcionamento adotadas pelo grupo? Que significados atribuem ao futebol que praticam? Como a prática do futebol se insere nas suas vidas?

3. Consideramos o Futsal um derivado do futebol, tanto pelas suas características funcionais, quanto pelo fato de que também é um esporte, no Brasil, considerado masculino. Por essas razões, e também pelo fato de que as mesmas mulheres também praticam o futebol, daqui para frente trataremos igualmente o futsal e o futebol. 
Em busca de respostas para essas questões, realizamos um estudo etnográfico desenvolvido em 12 meses de trabalho de observação participante, ${ }^{4}$ que se desenvolveu de agosto de 2006 a agosto de 2007. Observando e participando de treinos e jogos do grupo investigado, realizamos 5 I idas a campo, principalmente nos encontros semanais, que eram aos sábados e aos domingos, e tinham a duração de três horas aproximadamente. Além destes encontros que eram coletivos, e no contexto da prática do futsal, vivenciamos outros momentos do cotidiano das integrantes do grupo, alguns individuais e outros com parte dos seus integrantes; isto ocorreu em festas de aniversário, em conversas de bar após os jogos, em almoços, em jantares e em outros momentos que faziam parte da dinâmica extra-campo do grupo. Esses contatos também ocorreram na realização das entrevistas ( I7) que foram realizadas com participantes da equipe.

Entendendo que as entrevistas são "um ouvir todo especial" (OLIVEIRA, 1998, p. 22) e que deveriam obedecer ao "princípio de diversificação das pessoas" (RUQUOY, 1997, p. 103), elas tiveram a característica de serem do tipo semiestruturada, e foram realizadas dois meses após o término da observação participante - essa estratégia possibilitou escolher os informantes que consideramos importantes para o grupo investigado, permitindo abranger diferentes aspectos da realidade observada. As entrevistas foram transcritas e devolvidas às pessoas entrevistadas; após este processo de validação, cada informante autorizou o uso do material obtido, através da assinatura do Termo de Consentimento Livre e Esclarecido.

Outra fonte de informações foi a utilização da internet: autorizados pelo grupo, tivemos acesso a cerca de 150 mensagens que circulavam entre as jogadoras e também às conversas travadas pela comunidade criada pelo grupo (ORKUT).

\section{DA SOCIALIZAÇÃO AO FUTEBOL À FORMAÇÃO DA EQUIPE AMADORA}

As trajetórias esportivas das praticantes que hoje compõem o Time $^{5}$ investigado são semelhantes, em relação ao futebol. Várias delas declararam que iniciaram a jogar futebol desde a infância, quando praticavam na rua e entre os meninos. Helena é uma das inte-

4. "Considerada condição necessária para qualquer investigação de caráter antropológico, a observação participante consiste - em linhas gerais - na vivência do investigador, por um longo período, no contexto que pretende investigar; é nesta experiência que ele - um estrangeiro no universo cultural em que está agora envolvido - estará em contato com modos de vida onde estão presentes diferentes sistemas de significação, valores e comportamentos sociais que é preciso desvelar" (STIGGER, 2007, p. 39).

5. Para não expor o nome da equipe investigada, ela será nomeada de "Time". 
grantes da equipe que, quando questionada sobre o assunto, afirma: "eu jogo desde que me conheço por gente. Quando pequenininha jogava com os guris na terra vermelha, no interior, Santo Augusto" (HELENA, 22/5/2007)".

Esse tipo de socialização no futebol se aproxima dos achados de outros estudos sobre mulheres/meninas praticantes desse esporte. Damo (2007) e Thomassim (2007), por exemplo, perceberam as meninas tendo a sua iniciação no futebol junto a grupos de meninos. Porém, comparando os resultados desses dois trabalhos, foi possível observar diferenças no que se refere à forma como os meninos e as meninas se identificam ao praticar o futebol, quando o fazem juntos. O estudo de Damo (2007) - realizado entre jovens de classe média e num bairro próximo ao centro de uma cidade (Porto Alegre), - mostrou uma grande resistência dos meninos em relação à presença de uma menina nos seus encontros esportivos; e a mesma resistência ocorria por parte dos seus pais acerca do fato da sua filha gostar de jogar o futebol. Já Thomassim (2007, p. 105), em estudo desenvolvido na periferia da mesma cidade e entre crianças pobres, observou que a presença de meninas entre os meninos era algo "invisível"; naquele estudo, perguntado sobre como via a presença de uma guria no grupo de meninos, Duda (um dos meninos) respondeu: "que guria?". Essas informações mereceriam mais atenção, mas por hora e devido aos limites desse texto, apenas sugerimos que há a necessidade de estudos que articulem, além de esportes e gênero, a categoria classe social.

Outra característica do processo de socialização ao universo do futebol das praticantes é reconhecer o "pai" como uma pessoa importante. Para a informante Luana, o apoio do seu pai para jogar futebol foi incentivador: "meu pai treinava um time de futebol, e tinha orgulho que eu jogava futebol. Eu até comecei a jogar porque ele me levava para as quadras... e daí ficavam os filhos dos jogadores e eu ... e eu jogava com eles" (LUANA, 25/9/2007).

Essa forma de iniciação também foi constatada por Menesson (2005), em uma pesquisa realizada entre jogadoras profissionais de futebol na França. Porém, se no Time por nós investigado foi revelada a presença do pai apenas quando elas eram crianças e iniciavam a prática do futebol, Menesson (2005, p. 74) percebe a participação paterna de forma mais prolongada, no decorrer de toda a carreira esportiva profissional das jogadoras. No caso da futebolista Celi, informante de Menesson, "o apoio de Bernad [pai de Celi] à prática da sua filha vai bem além de sua entrada nas atividades".

Contudo, apesar de muitas jogadoras não terem o apoio do pai para continuarem a praticar o futebol após a infância, elas permaneceram praticando. E a partir disso foi possível a formação do Time. A equipe surgiu a partir da iniciativa de duas jogadoras, com a ajuda de Pedro (professor de educação física e atual técnico 
voluntário da equipe), que reuniram algumas praticantes de futsal já conhecidas. Hoje, fazem parte do Time 17 jogadoras, ${ }^{6}$ e também pessoas a ele vinculadas de diferentes formas, mas sempre a partir de algum tipo de relação com as participantes: são amigos, amigas, namorados, namoradas, maridos, companheiras, ${ }^{7}$ filhos e sobrinhos que estão sistematicamente presentes em diversas atividades.

A rotina do Time era caracterizada por treinos e jogos. $\bigcirc$ que as participantes do grupo denominam de "treino" é uma atividade semanal (duas horas) que acontece em quadra alugada mensalmente, com dia e horário fixos. Os treinos observados eram subdivididos em dois momentos: durante a primeira hora, eram feitos exercícios específicos de fundamentos do futsal e, após esse período, acontecia um jogo. Algumas vezes o jogo era realizado entre as praticantes da própria equipe; em outras, era um amistoso contra times convidados.

Time também participa do que denomina de "jogos", que são aqueles realizados em torneios e em campeonatos. Os torneios são competições que acontecem em um ou dois dias, no máximo. Esses jogos são realizados nos três turnos, em um único ginásio. As equipes participantes dos torneios permanecem todo o dia esperando a sua vez de jogar e observando as partidas que acontecem no local. Nos campeonatos, que duram cerca de quatro meses, os jogos são realizados em dias e horários diversos. Aqui, diferentemente dos realizados durante os torneios, as equipes chegam ao ginásio, jogam e vão embora, pois não costumam acontecer outras partidas no mesmo dia.

A partir dessa rotina de treinos, torneios e campeonatos, o Time vai se constituindo e se apropriando de uma maneira particular de jogar o futsal. Ao lançar um primeiro olhar sobre o universo investigado, é possível pensar que os significados atribuídos pelas praticantes para o futsal se aproximam daqueles que estão presentes nos esportes de alto nível, apesar de ser um esporte praticado nos momentos de lazer das investigadas. A competitividade, o querer ganhar, a busca pelo rendimento esportivo na participação em torneios e campeonatos, são características presentes no Time que possibilitariam concordar com Rigauer (198|, p. 107), quando diz que "o esporte recreativo [...] acaba por ser uma versão em miniatura do esporte de alto nível".

Contudo, isso não acontece sempre, sendo possível relativizar a posição do autor. Compreendemos desta forma, pois, ao mesmo tempo em que o Time

6. As jogadoras têm entre 16 a $4 \mathrm{I}$ anos de idade. A maioria reside em Porto Alegre, enquanto outras em cidades próximas. Elas possuem profissões diversificadas e há, ainda, aquelas que estudam.

7. Termo nativo que expressa a ideia de um convívio conjugal (ou quase conjugal), porém sem vínculo legal. Entre estes se incluem os namorados e as namoradas. 
apresenta essas características, também há outras peculiaridades que foram identificadas a partir de uma análise de dentro. Nos momentos dos treinos, além da preocupação do técnico em inserir brincadeiras nos momentos de exercícios de fundamentos do futsal, uma lógica lúdica faz com que aquele ambiente seja descontraído. Nesses momentos pratica-se o que Loret (1996, p. 212-213) denomina de "esporte de utilidade lúdica": uma prática do tipo "'selvagem' [que] não possui [...] nenhum valor de troca $[\mathrm{e}][. .$.$] exalta somente um valor de uso limitado no tempo".$

Mas além desses aspectos de seriedade e divertimento presentes no jogar futsal, existem outros aspectos que chamam atenção no time investigado: as questões relativas ao gênero e à sexualidade.

\section{JOGANDO COM AS FEMINILIDADES: O JOGAR FUTEBOL ENTRE MULHERES}

As participantes do Time inserem as suas práticas esportivas entre as suas atividades de lazer, ${ }^{8}$ já que as vivenciam em momentos de não trabalho e são voltadas para o seu interesse próprio (DUMAZEDIER, 1973; ELIAS \& DUNNING, 1992). São atividades que fazem parte do universo do futebol amador da cidade, que, apesar de terem uma participação voluntária, atraem um conjunto significativo de praticantes. ${ }^{9}$ Contudo, apesar da liberdade de escolha quanto a frequentar ou não o grupo, lá estando, elas passam a assumir compromissos tanto nos treinos que semanalmente são desenvolvidos, quanto nos jogos dos quais participam em torneios e campeonatos. Com esse espírito, estratégias e hierarquias foram sempre visíveis, já desde o momento em que alguma jogadora se candidatava a se inserir no Time. Para ser aceita, uma potencial integrante necessita passar por um teste capaz de mostrar que tem "capital esportivo" (MARIVOET, I 998, p. 31 ) 10 compatível com a equipe. $\bigcirc$ modo de ingresso, portanto, é um indicativo de que a performance/ rendimento perpassa a maneira como o Time vivencia o esporte.

Mas a admissão também deve ocorrer através de convite/indicação das candidatas, onde outras qualidades são avaliadas, é fundamental comparecer nos dias e horários acordados e dedicar-se com seriedade ao grupo, já que, nesse universo, não comparecer ao treino e/ou ao jogo sem avisar/justificar é considerado uma falta grave. Sinal da importância de assumir compromissos está no argumento de Ana,

8. Ver maiores informações em Stigger e Silveira (2010).

9. Num dos campeonatos de que as nossas colaboradoras participaram, haviam 20 equipes inscritas, perfazendo um total aproximado de 200 mulheres.

10. O conceito de capital esportivo cunhado pela autora está relacionado com o conceito de capital cultural, utilizado por Bourdieu em várias obras. 
ao explicar porque não convidar algumas boas jogadoras para participar o Time: "não, porque elas não têm muita vontade de treinar".

Outro aspecto importante para uma jogadora permanecer na equipe refere-se à questão da feminilidade e sexualidade. Identificamos várias mulheres homossexuais (inclusive casais) fazendo parte do Time. " Presenciamos também diferentes maneiras de vivenciar a feminilidade, desde a feminilidade hegemônica da sociedade até feminilidades que se afastam dessa. Contudo, quando a maneira de ser feminina de uma mulher se aproxima da masculinidade hegemônica da sociedade, as praticantes investigadas parecem depreciá-la. Para a jogadora Laura, as mulheres que possuem uma feminilidade próxima da masculinidade hegemônica, tanto em termos estéticos quanto comportamentais, não são bem vistas por ela. Denise, também jogadora do Time, concorda com a opinião de Laura, afirmando que a opção sexual não pode ser um motivo para uma feminilidade próxima da masculinidade hegemônica: "Acho que se tu é mulher, tem que se vestir como tal. E não... sabe... tu pode ter a tua opção [sexual], mas tu não precisa ... tipo virar um... um homem, entendeu?" (DENISE, 21//0/2007).

Essa posição se assemelha com o que Meinerz (2005, p. 84) identificou em sua pesquisa com mulheres homossexuais da classe média: "encontrei no campo uma depreciação da mulher masculinizada, qualificada como caminhoneira, que usa roupas e adota comportamentos tipicamente relacionados ao gênero masculino". O termo "caminhoneira" também foi encontrado por Dornelles (2004), em estudo realizado no âmbito do futebol feminino em Porto Alegre, e é usado para classificar

as mulheres [...] que participam do futebol feminino, mas que, também, são homossexuais e apresentam uma construção corporal e gestual próxima das características que foram construídas social e historicamente como masculinas (DORNELLES, 2004, p. 32).

A expressão "caminhoneira" não foi observada nessa investigação, mas percebemos que a depreciação das mulheres "masculinizadas", como denominaram as nossas colaboradoras, ali também acontecia. Elas acreditam que a masculinização das mulheres dentro do universo do futsal "rotula" esse esporte. Segundo a opinião da maioria das jogadoras homossexuais com quem tivemos contato naquele contexto, as pessoas "são levadas a caracterizar o homossexual pela fisionomia" (LAURA, 30/I0/2007). Logo, ter mulheres que possuam traços corporais e gestos próximos das características construídas social e historicamente como masculinas

1 I. Essa identificação aconteceu durante o período de observação da pesquisa, de modo gradual. Pois, ao nos aproximar das integrantes da equipe investigada, passamos a participar das conversas em que o tema da homossexualidade era central. Nessas conversas, elas discorriam sobre o expressivo número de praticantes de futsal que tinham como orientação a homossexualidade e também falavam sobre orientações sexuais das participantes do próprio grupo. 
faz com que o futsal seja visto - pejorativamente - como um universo de mulheres homossexuais, além de reforçar o vínculo desse esporte com o universo masculino. Por essa razão Luana afirma ser necessário tirar o rótulo do futebol feminino, ou seja, desfazer a associação entre futebol feminino-masculinização-homossexualidade. "A gente não tem que rotular o futebol feminino. Tem que tirar esse rótulo dele" (LUANA, 25/9/2007).

Segundo as informantes, rotular o universo do futebol feminino prejudica esse esporte. Em primeiro lugar, a rotulação favorece a exclusão de mulheres que gostam de futebol e futsal, mas que não são homossexuais:

Se a gente rotular o nosso time, a gente tá colocando de fora a Graciele, a Ana, a Helena, que são pessoas [heterossexuais], são maravilhosas assim como ser humano, entende. Então eu acho que o rótulo, ele também serve pra bloquear isso. Por isso que eu acho que o futebol ficou tão cheio de, de lésbicas, por causa disso. Porque quem não era e gostava de futebol acabou, sei lá, não jogando ou praticando (...). Eu acho que por isso que eu sempre fui uma adepta a lutar contra esse tipo de rótulo (LAURA, 30/I 0/2007).

Outro aspecto que é destacado como negativo e está relacionado à rotulação do futebol é a falta de patrocínios para as equipes femininas. Laura acredita que, devido ao preconceito da sociedade para com os homossexuais, dificilmente a mídia vai apoiar o futebol feminino que, até então, está associado à masculinização da mulher e à homossexualidade.

Assim, a maioria das integrantes da equipe investigada não apóia a entrada no Time de mulheres com aparência e trejeitos que se assemelham à masculinidade hegemônica da sociedade. Ali há diferentes tipos de feminilidade que são respeitados, mas nenhuma jogadora adota uma feminilidade muito próxima das características que foram social e historicamente construídas como masculinas. Em outras palavras, como nenhuma integrante pode ser identificada como "caminhoneira" ou "masculinizada", naquele universo o gênero torna-se - assim como a performance esportiva - um instrumento de hierarquização.

Se no universo do futebol de várzea de Porto Alegre, como identificou Dornelles (2004, p. 30), há diversos grupos de jogadoras "desde as 'patricinhas' e 'profissionais', 'caminhoneiras' e 'festeiras', até as 'bairristas' e as 'boleiras'”, no universo do futsal não é diferente, tendo sido possível identificar, no decorrer da pesquisa, inúmeros grupos de jogadoras quanto às características de gênero. Contudo, em relação ao Time no qual aprofundamos nossas observações, os grupos formados pelas praticantes não eram tão nítidos. $\bigcirc$ único grupo que visivelmente não havia na equipe era o das "caminhoneiras", já que elas não eram ali aceitas. Consideramos, assim, que, mesmo num contexto em que o preconceito em relação 
à homossexualidade feminina é quase inexistente, observa-se discriminação com relação ao gênero: se no grupo há várias mulheres homossexuais, o mesmo não ocorre com relação às jogadoras "masculinizadas" ou "caminhoneiras". Dessa forma, pode-se afirmar que é nos aspectos relativos ao gênero - e não à sexualidade - que elas estabelecem um meio de hierarquia. ${ }^{12}$

Apesar de ter essas características frente às feminilidades, o jogo de futsal praticado pelo Time não deixa de ter características associadas à masculinidade hegemônica. Nos momentos de treinos e competições, esses aspectos por elas considerados próprios de mulheres (não ser masculina), muitas vezes, eram vivenciados juntamente com gestos viris ditos masculinos. Assim, se os comportamentos femininos são evidentes nas vestimentas e fora do jogo, durante as partidas as jogadoras atuam dentro de padrões normalmente associados aos homens. Não raramente elas dividem a bola utilizando o corpo de forma viril e até violenta. Com frequência, após os jogos, as praticantes estudadas ficaram com marcas no corpo provocadas pelas jogadas mais duras ou agressivas, situações em que hematomas, inchaços, arranhões e outras lesões eram comuns em seus corpos.

Porém, preocupadas em manter um corpo dentro de padrões femininos, as nossas colaboradoras sempre buscavam esconder os sinais resultantes dos seus encontros esportivos. Um exemplo foi quando Glória usou maquiagem para encobrir um hematoma na perna; outro exemplo foi Valéria (que é goleira do Time) não querer fotografar as suas unhas (pintadas) após o jogo, justificando que, naquele momento, seus dedos estavam "feios", pelos inchaços decorrentes da prática do futebol. Já a jogadora Graciele, ao falar das vestimentas que utiliza para jogar, afirma que "pode ver...se eu to na quadra, ta alguma coisa combinando. Alguma coisa tem que combinar, senão não jogo" (GRACIELE, 17/9/2007).

Esse comportamento é bem diferente do que acontece com os homens, em esportes (inclusive no futebol) onde marcas corporais são encaradas como símbolos que lhes dão status nos seus respectivos contextos. $\bigcirc$ que fazem as mulheres pesquisadas difere de como agem os homens praticantes de "Vale Tudo", esses que se orgulham de mostrar as suas orelhas deformadas, como forma de evidenciar seu pertencimento a um grupo que tem na violência e na resistência à dor, um dos seus importantes referenciais masculinos (NUNES; GOELLNER, 2007).

12. Segundo uma pesquisa realizada por Adelman (2003, p. 449) com jogadoras de vôlei profissional e com amazonas do hipismo clássico sobre "o que está em jogo quando as mulheres se tornam atletas" (p. 449), as feminilidades das atletas se diferenciam em relação ao tipo de prática esportiva que as mulheres estão inseridas. Para a autora "a persistência de grande ambivalência em relação ao significado da atividade física e esportiva das mulheres sugere que esta seja um dos mais importantes espaços de conflito relativos à definição da corporalidade feminina na atualidade, com certeza, vinculado àquele outro campo de conflito, o da sexualidade". 
Contudo, se muitas vezes elas se afastam de características consideradas masculinas, em outros momentos das observações pudemos constatar que as jogadoras do Time se comparam aos homens. Observamos que as praticantes de futsal analisavam as jogadas das outras a partir do que consideram um bom futebol: o futebol masculino. Não identificamos muitas comparações com jogadoras mulheres, mas sim, várias comparações com jogadores homens. A fala de uma das praticantes em relação a uma goleira do Time é exemplo da comparação realizada com o futebol praticado pelos homens: "ela se atira que nem goleiro mesmo na bola" (GRACIELE, 17/9/2007). ${ }^{13}$

A informante Graciele também expressa essa comparação com o futebol masculino a partir da opinião de seu pai sobre o modo dela jogar futebol: "eu só concordo com ele [pai de Graciele]... eu tinha que ter nascido homem, como se diz... eu tenho que concordar com ele, né? Porque eu teria tido mais oportunidade" (GRACIELE, 17/9/2007). Essa fala mostra que Graciele, da mesma forma que seu pai, visualiza o futebol praticado por ela a partir daquele jogado pelos homens. Se ela tinha que ter nascido homem é porque o jogar dela é compatível com aquele esperado dos homens. Está implícito aí que Graciele possui um "capital esportivo" (MARIVOET, I998, p. 3 I) tão bom que merece ser comparado com o de um jogador.

Dessa forma, a prática do futsal por mulheres no grupo investigado ultrapassa os limites da quadra. Fazer parte do Time requer muito mais do que saber jogar o futebol. No que se refere à apropriação por elas, de um esporte socialmente considerado masculino, as questões de gênero estão presentes desde a admissão de uma nova participante até a finalização do jogo, quando elas querem esconder as marcas deixadas pelas jogadas mais duras.

\section{CONSIDERAÇÕES FINAIS}

Este estudo buscou compreender de que maneira acontece o associativismo de um grupo de mulheres praticantes de futsal na cidade de Porto Alegre. Dentre as preocupações que envolveram a pesquisa estavam o lazer esportivo de muIheres e a presença delas num esporte considerado socialmente masculino. Essas preocupações, que formam o corpo da pesquisa, foram frutos da constatação do pequeno número de estudos que abordam essas temáticas. Se mulheres praticantes de esportes já é um assunto pouco tratado nas investigações sociológicas, o tema mulheres praticantes de esportes socialmente considerados masculinos em momentos de lazer é menor ainda.

13. Grifo nosso. 
Investigar esse universo particular nos permitiu constatar que o associativismo esportivo dessas mulheres se pautava por inúmeros tipos de interações sociais que ocorriam dentro e fora do campo de jogo. Na equipe observamos vínculos de parentesco, relações profissionais, aproximações por companheirismo, mas, em especial, encontramos vínculos esportivos, relações homossexuais e de amizade. São essas relações que fazem as pessoas do Time se encontrarem em todos os finais de semana: é por gostarem de esporte, por terem em comum a opção homossexual e por compartilharem relações de amizade que o time se mantém. ${ }^{14}$

Contudo, ressaltamos que, mesmo sendo esses os sustentáculos do associativismo estudado, isso não significa que todos os integrantes compartilhem esses vínculos igualmente. Deve-se ter o cuidado para não deslizar as análises de um grupo para uma análise em escala individual. Os significados que cada integrante atribui ao time variam. Mesmo que todas se aproximem no que se refere ao gosto pelo futsal, algumas delas fazem parte da equipe apenas por essa razão, enquanto outras permanecem nela também pelas relações de amizade. Se algumas jogadoras são homossexuais e encontraram naquele espaço de lazer uma possibilidade de vivenciar a sua opção sexual, outras são heterossexuais e também estão ali para terem seus momentos de fruição de uma prática com a qual se identificam.

A investigação ainda nos possibilitou compreender que os significados atribuídos por mulheres a um esporte socialmente dito masculino envolvem o extrapolar do jogo propriamente dito, e a necessidade de ampliar a discussão para as questões de gênero e sexualidade ali envolvidas, inclusive fora da quadra. Esses temas se entrelaçam com o cotidiano das jogadoras, que reforçam a dimensão social e política que elas assumem juntamente com o esporte que escolheram praticar.

Contudo, se é evidente que elas rompem com normas sociais que determinam aspectos hegemônicos do comportamento feminino, fica manifesto, no grupo, que as feminilidades lá constituídas se aproximam em diversos momentos daquelas que são esperadas pela sociedade. Logo, podemos afirmar que as mulheres que investigamos fazem do jogar futebol um jogo das feminilidades e sexualidades onde, como diria Louro (200 I , p. 32), "borram-se fronteiras".

14. A temática original dessa investigação se relacionou ao esporte, à homossexualidade e à amizade, tendo sido sempre perpassada pela noção de gênero. Pelo limites impostos a esse artigo, tratamos aqui especialmente do que se refere ao esporte e ao gênero. 
Laying with femininity: Ethnographic study on an indoor soccer team from Porto Alegre

ABSTRACT: This study approaches the sporting associativism of women. It is an ethnographic investigation developed in the context of a female indoor soccer team, in which we seek to understand the reason why women associate to practice a so-called masculine sport, and the way this practice is inserted in their lives. After one year of participating observations (field diaries) and interviews ( 17), we identified that the practice of indoor soccer extrapolates the sport per se, being strongly attached to issues of gender and sexuality present inside and outside the court. In the relation with the sport that they chose to practice, these issues are interlaced in the players' everyday heterogeneously: if on the one hand we can identify a transgression of dominant standards, on the other we can see a reproduction of these values. KEY-WORDS: Gender; sexuality; indoor soccer; women.

\section{Jugando con las feminidades: Um estudio etnográfico en un equipo de fútbol de salón femenino de Porto Alegre}

RESUMEN: Este estudio aborda el asociativismo deportivo de mujeres. Se trata de una investigación etnográfica desarrollada en el contexto de un equipo de fútbol de salón femenino, donde buscamos saber cómo y por qué mujeres se asocian para prácticar un deporte socialmente considerado masculino, y como esa práctica se inserta en sus vidas. Después de un año de observación participante (diarios de campo) y realización de entrevistas (17), identificamos que la práctica de fútbol de salón extrapola el juego propiamente dicho, siendo vinculada a las cuestiones de género y sexualidad presentes dentro y afuera de la cancha. En la relación con el deporte que ellas eligieron prácticar, eses temas se entrelazaban en el cotidiano de las jugadoras de forma heterogénea: si por un lado, identificamos una transgresión en relación a los padrones dominantes, por otro, también visualizamos la reproducción de esos mismos valores. PALABRAS CLAVES: Género; sexualidad; futsal; mujeres.

\section{REFERÊNCIAIS}

ADELMAN, M. Mulheres atletas: re-significações da corporalidade feminina. Estudos Feministas. Florianópolis, v. II , n. 2, p. 445-465, jul./dez. 2003.

COSTA, L. M. O que é uma torcedora? notas sobre a representação e auto-representação do público feminino de futebol. Esporte e Sociedade, Niterói, ano 2, n. 4, nov. 2006/fev. 2007.

DAMO, A. S. A rua e o futebol. In: STIGGER, M. P.; GONZÁLEZ, F.; SILVEIRA, R. O esporte na cidade: estudos etnográficos sobre sociabilidades esportivas em espaços urbanos. Porto Alegre: Ed. da UFRGS, 2007, p. 51-70.

DORNELLES, P. G. O futebol feminino de várzea: uma análise cultural. 2004. 39f. Trabalho de Conclusão de Curso (Especialização em Pedagogias do Corpo e da Saúde) - Escola de Educação Física, Universidade Federal do Rio Grande do Sul, Porto Alegre, 2004. 
DUMAZEDIER, J. Lazer e cultura popular. São Paulo: Perspectiva, 1973.

DUNNING, E. O desporto como uma área masculina reservada: notas sobre os fundamentos sociais na identidade masculina e as suas transformações. In: ELIAS, N.; DUNNING, E. A busca da excitação. Lisboa: Difusão Editorial, 1992. p. 389-4I2.

ELIAS, N.; DUNNING, E. O lazer no espectro do tempo livre. In: ELIAS, N.; DUNNING, E. A busca da excitação. Lisboa: Difusão Editorial, 1992, p. 139-184.

FRANZINI, F. Futebol é "coisa para macho"? Pequeno esboço para uma história das mulheres no país do futebol. Revista brasileira de História, São Paulo, v. 25, n. 50, p. 3 I 5- 328, jul./ dez. 2005.

GOELLNER, S. V. Mulher e esporte no Brasil: entre incentivos e interdições elas fazem histórias. Pensar a Prática, Goiás, v. 8, n. I , p. 85-100, jan./jun. 2005a.

GOELLNER, S. V. Mulheres e futebol no Brasil: entre sombras e visibilidades. Revista Brasileira de Educação Física e Esporte, São Paulo v. 19, n. 2, p. |43- I 5 I, jun. 2005 b.

GUTTMANN, A. From ritual to record: the nature of modern sports. New York: Columbia University, 1978.

LORET, A. Génération glisse: dans l'eau, l'air, la neige... la révolution du sport des "années fun". Paris: Autrement, 1996.

LOURO, G. L. Pedagogias da sexualidade. In: . O corpo educado: pedagogias da sexualidade. Belo Horizonte, Autêntica, 200I. p. 7-34.

MARIVOET, S. Aspectos sociológicos do desporto. Lisboa: Livros Horizontes, 1998.

MEINERZ, N. E. Entre mulheres: estudo etnográfico sobre a constituição da parceria homoerótica feminina em segmentos médios na cidade de Porto Alegre - RS. 2005. Dissertação (Mestrado em Antropologia social) - Instituto de Filosofia e Ciências Humanas, Universidade Federal do Rio Grande do Sul, Porto Alegre, 2005.

MENNESSON, C. Être une femme dans le monde des hommes: socialisation sportive er construction du genre. France: L'Harmattan, 2005.

MENNESSON, C. Les processus de construction et de modification des dispositions sexuées des femmes investies dans um sport dit « masculin ». In: DEFRANCE, J. Societe de sociologie du sport de langue française, dispositions et pratiques sportives: débats actuels en sociologie du sport. France: L'Hamattan, 2004. p. 37-53.

MENNESSON, C. and CLÉMENT, J.-P. Homosociability and homosexuality: the case of soccer played by women. International Review for the Sociology of Sport, London, v. 38, n. 3, p. 3। |-330, mar. 2003

MOURÃO, L; MOREL, M. As narrativas sobre o futebol feminino. Revista Brasileira de Ciências do Esporte. Campinas, v. 26, n. 2, p. 73-86, jan. 2005. 
NUNES, C. R. F;; GOELLNER, S. V. O espetáculo do ringue: o esporte e a potencialização de eficientes corporais. In: COUTO, E.; GOELLNER, S. V. (Org.). Corpos mutantes: ensaios sobre novas (d)eficiências corporais. Porto Alegre: UFRGS, 2007. v. I. p. 55-72.

OLIVEIRA, R. C. O trabalho do Antropólogo: olhar, ouvir, escrever. In: . $O$ trabalho do antropólogo. São Paulo: Ed. da Unesp, 1998, p. 17-35.

RIGAUER, B. Sport and work. Ney York: Columbia University, 1981.

RUBIO, K.; SIMÕES, A. C. De espectadoras a protagonistas: a conquista do espaço esportivo pelas mulheres. Revista Movimento, Porto Alegre, v. 5, n. II , p. 50-56, 1999.

RUQUOY, D. Situação de entrevista e estratégia do entrevistador. In: ALBARELLO, L. et al. Práticas e métodos de investigação em ciências sociais. Lisboa: Gradiva, 1997. 84- 1 l 6.

SAOUTER, A. A mamãe e a prostituta: os homens, as mulheres e o rugby. Revista Movimento, Porto Alegre, v. 9, n. 2, p. 37-52, maio/ago. 2003.

SILVEIRA, R. Copa do mundo de 2006: o que elas escreveram na Folha de São Paulo. Pensar a Prática, Goiânia, v. I0, n. I p. 133-152, jan./jun. 2007.

STIGGER, M. P.; SILVEIRA, R. Ocio y homosexualidad: um estúdio etnográfico sobre el asociativismo deportivo de mujeres, em el contexto de um deporte dicho masculino. Revista Polis, Santiago, v. 9, n. 26, p. I-14, 2010.

STIGGER, M. P. Estudos Etnográficos em Esporte e Lazer: pressupostos teórico-metodológicos e pesquisa de campo. In: STIGGER, M. P.; GONZÁLEZ, F. J.; SILVEIRA, R. (Org.). O Esporte na Cidade: estudos etnográficos sobre sociabilidades esportivas em espaços urbanos. Porto Alegre: Editora da UFRGS, 2007, p. 3 I-50.

THOMASSIM, L. E. Imagens das crianças da periferia em projetos sociais esportivos. In: STIGGER, M. P.; GONZÁLEZ, F; SILVEIRA, R. (Org.). O esporte na cidade: estudos etnográficos sobre sociabilidades esportivas em espaços urbanos. Porto Alegre: Ed. da UFRGS, 2007. p. 97-। I5.

Recebido em: 19 maio 201 I

Aprovado em: 25 out. 2011

Endereço para correspondência:

Raquel da Silveira

Rua Fahum Nader Fares, 795

Bairro Cassino

Rio Grande-RS

CEP: 96208-190 